\title{
Gangguan Psikotik Akibat Stroke Iskemik
}

\author{
Rini Gusya Liza ${ }^{1}$, Bahagia Loebis²
}

\begin{abstract}
Abstrak
Stroke atau yang disebut juga dengan penyakit serebrovaskuler berkontribusi terhadap timbulnya delusi dan halusinasi di kemudian hari.Pengobatan yang diberikan pada kondisi medis sering menghasilkan remisi dari psikosis tetapi hal tersebut tidaklah selalu terjadi. Gejala psikosis dapat bertahan lama setelah kondisi medis yang menyebabkannya sembuh. Dilaporkan seorang pasien yang mengalami gangguan psikotik setelah mengalami stroke iskemik. Gangguan psikotik akibat stroke iskemik merupakan suatu kasus dalam Consultation Liaison Psychiatry.
\end{abstract}

Kata kunci: gangguan psikotik, stroke iskemik, delusi dan halusinasi

\begin{abstract}
Affiliasi penulis: 1. Bagian IImu Kedokteran Jiwa, Fakultas Kedokteran Universitas Andalas/RSUP Dr. M. Djamil Padang, 2. Bagian IImu Kedokteran Jiwa Fakultas Kedokteran Universitas Sumatera Utara

Korespondensi: Rini Gusya Liza, E-mail: rinigusya@yahoo.com, Telp: 0751-24451
\end{abstract}

Stroke or also called cerebrovascular disease contributed to the emergence of delusions and hallucinations in the future. Treatment given to medical conditions often produce remission of psychosis but it is not always happen. Psychotic symptoms can persist longer after recovery. Reported a patient who suffered a psychotic disorder after ischemic stroke. Psychotic disorders due to ischemic stroke is a case in Consultation Liaison Psychiatry

Keywords: psychotic disorder, ischemic stroke, delusions and hallucinations

\section{PENDAHULUAN}

Psikosis merupakan gangguan mental dimana pikiran, respons afektif, kemampuan mengenali realitas dan kemampuan untuk berkomunikasi ataupun berhubungan dengan orang lain yang sangat terganggu, dimana karakteristik klasik psikosis adalah gangguan tes realitas, halusinasi, delusi dan ilusi. Gangguan psikosis akibat kondisi medis umum harus dibedakan dengan gangguan psikotik primer contohnya skizofrenia, gangguan waham, gangguan skizoafektif atau gangguan mood primer dengan gambaran psikotik. Diagnosis psikosis oleh karena kondisi medis umum dibuat ketika riwayat medis pasien, pemeriksaan fisik atau hasil uji laboratorium menunjukkan satu atau lebih kondisi medis misalnya perubahan otak yang mungkin menimbulkan gejala psikotik, dan gejala psikotiknya (misalnya, halusinasi, waham) sebenarnya ada sejak kondisi medis terjadi. Banyak kondisi medis yang berbeda mampu menimbulkan psikosis. Kondisi neurologis yang dapat menyebabkan psikosis termasuk tumor otak, penyakit serebrovaskular, penyakit Huntington, multipel sklerosis, epilepsi, gangguan atau trauma neuron visual atau pendengaran, tuli, migrain dan infeksi sistem saraf pusat. ${ }^{1,2}$ Stroke atau yang disebut juga dengan penyakit serebrovaskuler berkontribusi terhadap timbulnya delusi dan halusinasi di kemudian hari. ${ }^{3}$ Pengobatan yang diberikan pada kondisi medis sering menghasilkan remisi dari psikosis tetapi hal tersebut tidaklah selalu terjadi. Gejala psikosis dapat bertahan lama setelah kondisi medis yang menyebabkannya sembuh. ${ }^{1,4}$

Tujuan laporan kasus ini adalah untuk memahami simtom psikiatri yang dapat terjadi pada penderita stroke iskemik dan penatalaksanaannya.

Psikosis adalah komplikasi pasca stroke yang jarang terjadi. Insidennya kira-kira 1\%. ${ }^{3}$ Penelitian terhadap pasien stroke yang berusia lebih dari 60 tahun selama periode 9 tahun, hanya lima pasien yang diidentifikasi mengalami psikosis. Semuanya 
mengalami lesi pada frontoparietal kanan dan atropi subkorteks. Tiga dari lima pasien mengalami kejang pasca stroke. ${ }^{5}$

Informasi tentang mekanisme psikosis pasca stroke berasal dari penelitian terhadap lima pasien yang mengalami psikosis pasca stroke, mereka menemukan pada semua pasien memiliki lesi di hemisfer kanan, primer melibatkan regio frontoparietal. Bila dibandingkan dengan pasien lain yang tidak mengalami psikosis setelah dilakukan matching umur, pendidikan, ukuran dan lokasi lesi, pasien-pasien dengan psikosis sekunder memiliki atropi subkortikal yang lebih besar seperti diperlihatkan pada area yang luas pada kedua tanduk frontal dari ventrikel lateral dan korpus ventrikel lateral. Beberapa peneliti juga melaporkan tingginya frekuensi kejang pada pasien dengan psikosis sekunder. Kejang ini biasanya dimulai setelah timbulnya lesi otak tetapi sebelum awitan psikosis. Telah dihipotesiskan bahwa tiga faktor yang mungkin penting pada mekanisme halusinasi organik antara lain keterlibatan lesi hemisfer kanan dari kortek temporoparietal, kejang dan atropi otak subkortikal. ${ }^{6}$

Gambaran klinis stroke dapat menimbulkan spektrum yang bervariasi dari sindrom neurobehavior yang harus menjadi perhatian oleh praktisi kesehatan mental dalam mengevaluasi gejala psikiatri pada pasien. Efek neurobehavior yang dapat terjadi antara lain gejala afektif ataupun gejala psikotik yang dapat terjadi segera setelah serangan stroke atau beberapa bulan sampai beberapa tahun kemudian. Adanya penyakit otak yang mendasari akan mempunyai efek samping terhadap penyembuhan gejala neurobehavior. ${ }^{7}$

Episode psikosis (halusinasi dan waham) berkembang secara akut dan menetap selama beberapa hari sampai beberapa bulan. Selain itu dijumpai juga adanya riwayat kejang pada pasien tersebut. Ditemukan pada pasien-pasien yang mengalami fenomena halusinasi secara signifikan menunjukkan atrofi subkortikal daripada pasien-pasien kontrol, yang ditunjukkan dari perbedaan yang signifikan pada besarnya rasio frontal horn ventrikel lateral otak dan ventrikel ketiga otak. ${ }^{5}$ Halusinasi visual dapat terjadi akibat lesi vaskuler fokal di jaras visual lobus temporalis, parietalis dan oksipitalis. Halusinasi ini disebut juga release hallucinations, biasanya dijumpai pada pasien stroke denganlokasi lesi yang hampir sama. Pada pasien-pasien yang mengalami fenomena halusinasi secara signifikan menunjukkan atrofi subkortikal daripada pasien kontrol, yang ditunjukkan dari perbedaan yang signifikan pada besarnya rasio frontal horn ventrikel lateral otak dan ventrikel ketiga otak. ${ }^{5}$ Halusinasi visual dapat terjadi akibat lesi vaskuler fokal di jaras visual lobus temporalis, parietalis dan oksipitalis. Halusinasi ini disebut juga release hallucinations. Biasanya dijumpai pada pasien stroke dengan lesi di hemisfer kanan sehingga dapat menjelaskan peran hemisfer kanan pada proses persepsi visual. Isi halusinasinya bermacam-macam, berlangsung beberapa menit bahkan kadang-kadang sampai beberapa hari. Infark di lobus oksipital dapat menyebabkan halusinasi psychedelic yaitu pasien memvisualisasikan bentukbentuk geometrik, spiral, papan main dam dan lainlain. ${ }^{8}$ Halusinasi autoscopy yaitu pasien melihat gambar atau bayangannya sendiri. Halusinasi ini biasanya disebabkan oleh perdarahan subarachnoid. Kadang-kadang disertai waham yaitu pasien meyakini bahwa dirinya benar-benar dua disebut Dopplganger. Halusinasi akustik dapat disebabkan lesi struktur otak terutama dikorteks auditorik temporal, jarang disebabkan oleh lesi vaskuler. ${ }^{8} \quad$ Waham pada pasien pasca stroke sering ditemukan waham kejar, sindrom Capgras dan neutoscopy. Adanya waham penyangkalan penyakit (anosognosia) atau Anton's syndrome. Waham pasca stroke sering disebabkan oleh trombus atau perdarahan intraserebri pada temporoparietal kiri atau subkorteks. ${ }^{8}$

\section{KASUS}

HBM, perempuan (57 tahun), Janda, Kristen, Batak, SD, IRT, alamat Jl. Tani Asli Gg. Gloria no.2 Desa Tanjung Gusta Dusun II, di konsulkan ke Poliklinik Psikiatri RSUP HAM Medan pada tanggal 17 November 2011. Nomor Rekam Medik : 492404.

Alloanamnesis: Sari, Perempuan, 17 tahun, belum menikah, Kristen, Batak, SMA, hubungan dengan HBM: Anak HBM, akrab dengan HBM, kesan dapat dipercaya.

Sebab utama: sering marah-marah, 
pembicaraan kadang tidak nyambung, kadang senyum-senyum sendiri, bicara sendiri dialami HBM sejak 15 hari yang lalu.

Keluhan utama: badan terasa lemas, pusing, kaki dan lengan kiri terasa lemah.

Riwayat penyakit sekarang: 20 hari yang lalu, awalnya HBM merasa kepala pusing saat sedang bekerja di rumah, kemudian HBM tiba-tiba terjatuh dan tidak sadarkan diri lebih kurang 5 menit, HBM kemudian di bawa keluarga ke klinik di dekat rumah HBM dan dirawat, selama dirawat kaki dan tangan kiri OS terasa lemah dan sulit digerakan, lidah HBM juga terasa berat dan bicara celat. Setelah dirawat selama 3 hari keadaan HBM semakin memburuk, HBM mulai bicara-bicara sendiri dan senyum-senyum sendiri serta pembicaraan HBM kacau dan kadang tidak nyambung. HBM kemudian di rujuk ke IGD RSUP HAM dan dirawat di bangsal neurologi. Selama dirawat di bangsal neurologi, HBM sering marahmarah, bicara-bicara sendiri, senyum-seyum sendiri, HBM sering mengatakan mendengar suara-suara yang mengejeknya. HBM mengatakan ada tetangga yang ingin mencelakai dan telah mengguna-gunai dirinya.

Riwayat penyakit terdahulu: riwayat gangguan psikosomatik: tidak dijumpai, riwayat gangguan neurologi: menderita penyakit stroke 7 tahun yang lalu, HBM dirawat di RS.HAM tetapi pulang paksa karena tidak ada biaya, kemudian HBM tidak kontrol lagi, riwayat gangguan mental emosional: tidak dijumpai, riwayat gangguan medik lainnya: menderita hipertensi sejak 10 tahun yang lalu tetapi tidak kontrol.

Riwayat kehidupan pribadi: riwayat prenatal: tidak jelas, riwayat masa bayi dan anak: tidak jelas, riwayat masa remaja: banyak teman, kurang percaya diri, suka bergantung kepada orang lain. Riwayat pendidikan: sampai kelas $6 \mathrm{SD}$, hubungan guru dan teman biasa. HBM tidak pernah tinggal kelas, prestasi HBM: biasa. Riwayat pekerjaan: ibu rumah tangga. Riwayat percintaan, perkawinan dan rumah tangga. HBM tidak pernah pacaran, menikah $1 x$ dengan almarhum suami HBM. la dijodohkan oleh orang tua. HBM memiliki 7 orang anak. Suami HBM meninggal dunia karena sakit liver pada tahun 2006.

Riwayat keluarga: identitas orangtua Ayah: AM,
Kristen, Batak, Tidak Tamat SD, petani (almarhum). Ibu: CS, Kristen, Batak, Tidak Tamat SD, petani (almarhum). Kepribadian orang tua: ayah pemarah, tegas. Ibu: ramah, agak cerewet. HBM merupakan anak ke-dua dari lima bersaudara.

Kondisi sosial ekonomi saat ini: kurang, HBM tidak bekerja, mendapat bantuan biaya sehari-hari dari anak-anaknya. Gambaran kepribadian OS sebelum sakit: mudah bergaul, ramah. Stresor psikososial: tidak dijumpai. Riwayat bunuh diri: tidak dijumpai. Riwayat keluarga yang menderita penyakit jiwa: tidak dijumpai.

\section{Pemeriksaan Psikiatri Khusus}

Gambaran umum: penampilan: seorang perempuan, sesuai umur, kurang rapi, kesan tidak dapat mengurus diri sendiri. Tingkah laku dan aktivitas psikomotor: hipoaktif, lemah lengan dan tungkai kiri. Sikap terhadap pemeriksa: kurang kooperatif, kontak mata dijumpai.

Pembicaraan : isi kadang relevan kadang tidak, bicara celat, arus pembicaraan lambat, nada suara pelan, produktivitas kurang, perbendaharaan bahasa sedikit. Afek: inappropriate, mood: disforik, emosi lainnya: tidak dijumpai.

Bentuk pikiran umum: RTA terganggu, psikosis (+). Bentuk pikiran spesifik: jawaban yang tidak relevan. Isi pikiran: waham persekutorik (+),HBM mengatakan ada tetangga yang ingin mencelakai dan telah mengguna-gunai dirinya. Waham referensi (+)HBM mengatakan sering dijelek-jelekan dan digosipkan oleh tetangga.

Persepsi: Halusinasi pendengaran (+) yang mengatakan bahwa HBM sering mendengar suarasuara yang mengejeknya. Derealisasi dan depersonalisasi: tidak dijumpai. Mimpi dan fantasi: tidak dijumpai.

Sensorium: alertness compos mentis. Orientasi waktu: terganggu (HBM tidak tahu hari apa saat dilakukan wawancara), orientasi tempat: baik (HBM tahu sedang berada di rumah sakit apa), orientasi personal: baik (HBM tahu yang mana dokter dan perawat). Konsentrasi terganggu (HBM hanya dapat menghitung 100-7 sampai angka 93). Kalkulasi terganggu (HBM tidak dapat menjawab perkalian $15 \mathrm{x}$ 
5). Daya ingat jauh : baik (HBM tahu nama sekolah SD dulu), daya ingat agak lama: terganggu (HBM tidak ingat kapan kejadian gempa di Padang), daya ingat baru saja: baik (HBM tahu sarapan apa tadi pagi), daya ingat segera: terganggu (HBM tidak mampu mengulang 4 digit angka terakhir yang disebutkan oleh pemeriksa dengan benar). Pengetahuan umum: baik (HBM tahu nama presiden RI sekarang). Pikiran abstrak: baik (HBM tahu peribahasa panjang tangan).

Insight: derajat III (sadar akan penyakitnya tetapi dalam waktu bersamaan melempar kesalahan pada orang lain, pada faktor eksternal, atau faktor organik). judgement sosial: baik (HBM mau ikut jika ada gotong royong dikampungnya), judgment tes: baik (HBM tahu apa yang akan dilakukan bila menemukan sepucuk surat yang lengkap dengan perangkonya). Kemampuan mengendalikan rangsang dari dalam diri sendiri: terganggu.

\section{Pemeriksaan Fisik}

Status sekarang; sensorium: compos mentis. Tekanan darah: 160/90 mmHg. Frekuensi nadi: 80 kali/menit. Frekuensi nafas: 24 kali/menit. Suhu tubuh: $36,2^{\circ} \mathrm{C}$. Pemeriksaan umum; kepala: mata: reflex cahaya $+/+$; pupil isokor ka=ki; Telinga/hidung/mulut: dalam batas normal. Leher: tekanan vena jugularis normal, tidak dijumpai pembengkakan kelenjar. Thoraks: bentuk simetris fusiform. Jantung: iktus normal, suara tambahan (-). Paru: suara pernafasan vesikuler, suara tambahan (-). Abdomen: simetris, soepel, nyeri tekan (-), Hepar/lien/ren: tidak teraba. Kelamin: tidak dilakukan pemeriksaan. Ekstremitas: atrofi (-)

\section{Pemeriksaan Neurologik}

Sensorium: compos mentis. Tanda peningkatan TIK: tidak dijumpai. Tanda perangsangan meningeal: tidak dijumpai. Nervus kranialis: $\mathrm{N} \mathrm{I}$ : Normosmia, $\mathrm{N}$ II: Reflex cahaya +/+, pupil isokor, diameter $3 \mathrm{~mm}, \mathrm{~N}$ III, IV, VI: Gerakan bola mata (+) normal. N V: Motorik dan sensorik tidak dijumpai kelainan. N VII: Sudut mulut tertarik kekanan. N VIII: Pendengaran dalam batas normal. N IX, X: Disartria (-), uvula medial, disfagia (-). N XI: Mengangkat bahu (+) normal. N XII:
Lidah istirahat dan dijulurkan medial.

Sistem motorik;trofi/tonus: eutrofi/normotonus. Kekuatan otot, ekstremitas atas: kanan (5555), kiri (1111), extremitas bawah, kanan (5555), kiri (1111). Reflex fisiologis; kanan dan kiri; Biceps/Triceps: $(+/+,++)$, APR/KPR: $(+/+/+/+)$. Reflex patologis; kanan/kiri Hoffman-Trommer:(-)/(-). Babinski: (-)/(-), klonus kaki: (-)/(-). Sistem sensibilitas; eksteroseptif: tidak dijumpai adanya kelainan, propioseptif: tidak dijumpai adanya kelainan. Gangguan ekstrapiramidal: tidak dijumpai. Fungsi luhur: terganggu.

\section{Pemeriksaan Penunjang}

\section{a. Laboratorium}

$\mathrm{Hb}$ : $12 \mathrm{~g} / \mathrm{dl}$, Leukosit: 9,95 103/. $\mathrm{mm}^{3}$, Trombosit: $42210^{3} / \mathrm{mm}^{3}$. Hematokrit: 24,5\%. Eritrosit: 3,03 $10^{6} / \mathrm{mm}^{3}$. Hitung jenis: net/ limf/ mon/ bas/ eus: $76,3 /$ 16,7/ 5,9/ 0,54/ 0,54. Trigliserida: 109 mg/dl. Widal, titer: $1 / 40$

\section{b. Head CT Scan dengan kontras}

Hasil: Supratentorial tampak lesi hipodens di periventrikular kanan. Tidak tampak midline shift. Cortical sulci dan ventricular system normal. Kesan: Cerebral infarct di periventrikular kanan.

c. Pemeriksaan EKG: Kesan normal

Diagnosis banding: Gangguan psikotik akibat Stroke Iskemik, Demensia vaskular.

\section{Diagnosis Multiaksial}

Aksis I: Gangguan psikotik akibat Stroke Iskemik. Aksis II: Tidak ada diagnosis, ciri kepribadian dependen, mekanisme pertahanan ego: represi, proyeksi, introyeksi, distorsi, denial

Aksis III: Hemiparese sinistra ec. Stroke iskemik (infark serebri)+Hipertensi stage II

Aksis IV: Tidak ada diagnosis

Aksis V: GAF scale saat pemeriksaan: 40-31. GAF scale 1 minggu terakhir: 70-61. GAF scale satu tahun terakhir: 80-71. Skor BPRS (Brief Psychotic Rating Scale): 61

Defensive Functioning Scale; current defenses atau coping style: represi, isolasi, introyeksi, somatisasi, delutional projection, psychotic distortion, 
psychotic denial. Predominan current defence level: Level of defensive dysregulation. Prognosis: ragu-ragu menuju baik.

Penatalaksanaan; dari Bagian Psikiatri; Risperidon $2 \mathrm{mg} 1 \times 1 / 2$ tablet/oral/hari (malam), psikoedukasi keluarga, terapi suportif. Dari Bagian Neurologi: IVFD R Sol $20 \mathrm{gtt} / \mathrm{mnt}$, Inj Citicolin 1 amp/12 jam, Ranitidin 1 amp/12 jam, Captopril 3x25 $\mathrm{mg}$, Fisioterapi.

\section{PEMBAHASAN}

Pada kasus ini seorang perempuan, HBM, 57 tahun, didiagnosis dengan "Gangguan psikotik akibat kondisi medis umum" yaitu "Gangguan psikotik akibat stroke iskemik" berdasarkan hasil anamnesis, pemeriksaan fisik, pemeriksaan neurologis, pemeriksaan psikiatri dan pemeriksaan penunjang.

Pemeriksaan psikiatri mendapatkan seorang perempuan, sesuai dengan usia, tingkah laku dan aktivitas psikomotor: hipoaktif, lemah lengan dan tungkai kiri. Sikap terhadap pemeriksa: kurang kooperatif, pembicaraan: arus lambat, perbendaharaan sedikit, isi kadang relevan kadang tidak, afek: inappropriate, mood: disforik, bentuk pikiran: RTA terganggu, psikosis (+), asosiasi longgar, isi pikiran: waham persekutorik (+), persepsi: halusinasi pendengaran (+) yang mengatakan bahwa HBM mendengar suara-suara tetangga mengejek HBM, insight derajat III.

Hal ini sesuai dengan kriteria diagnostik DSMIV-TR untuk gangguan mental akibat kondisi medik umum. Kriteria Diagnostik Gangguan Psikotik akibat Kondisi Medis Umum menurut DSM - IV - TR: Halusinasi dan waham yang lebih menonjol, adanya bukti yang jelas dari riwayat, pemeriksaan fisik atau pemeriksaan laboratorium dimana gangguan tersebut merupakan konsekuensi langsung dari kondisi medis umum, gangguan tersebut bukan bagian dari gangguan mental lainnya dan gangguan tersebut tidak terjadi selama perjalan delirium.

Diagnosis banding adalah demensia vaskular sesuai dengan kriteria diagnostik DSM-IV-TR karena pada anamnesis dan pemeriksaan psikiatri dijumpai gangguan memori (daya ingat segera), adanya gangguan berbahasa yaitu bicara celat, arus pembicaraan lambat, nada suara pelan, produktivitas kurang, perbendaharaan bahasa sedikit, dari pemeriksaan neurologi didapatkan kelemahan extremitas kiri, sudut mulut tertarik ke kanan, pemeriksaan CT scan menunjukan adanya infark paraventrikuler. Diagnosis ini disingkirkan karena pada HBM yang lebih menonjol gejala psikotiknya berupa RTA yang terganggu, adanya waham dan halusinasi. Sedangkan kemampuan kognitif lain seperti atensi, fungsi eksekutif dan visio-spasial masih baik, dimana kemampuan berpikir abstrak HBM masih baik, orientasi tempat dan personal masih baik.

Pada aksis II tidak ada diagnosis, dijumpai ciri kepribadian dependen dimana HBM membiarkan orang lain untuk mengambil sebagian besar keputusan penting bagi dirinya yaitu HBM menikah dijodohkan oleh orang tua dan HBM terpaku pada ketakutan akan ditinggalkan oleh orang yang dekat dengannya dan ditinggalkan agar mengurus diri sendiri, setelah orangtua meninggal dunia, HBM kemudian bergantung pada suaminya, setelah suaminya meninggal, HBM merasa kehilangan sosok untuk bergantung, HBM merasa tidak berdaya karena hanya suami OS yang bekerja mencari nafkah, sekarang HBM mengharapkan bantuan biaya hidup dari anakanaknya.

HBM menggunakan mekanisme pertahanan ego introyeksi dimana HBM menyalahkan dirinya karena tidak mampu membahagiakan keluarganya. Sedangkan menggunakan mekanisme pertahanan ego distorsi dimana ego telah mengubah kenyataan yang ada untuk menyesuaikan dengan sesuatu yang datang dari dalam dirinya (inner need) yaitu waham persekutorik, waham referensi dan halusinasi pendengaran, dimana OS meyakini bahwa ia benarbenar selalu diejek dan dihina orang lain. Ketika ditanya masalah kematian suaminya, HBM sepertinya menyembunyikan kesedihannya, oleh karena HBM menggunakan mekanisme pertahanan ego isolasi. HBM juga menggunakan mekanisme pertahanan ego denial yaitu HBM menyangkal kalau ia sakit karena faktor dari dirinya tapi ia menyalahkan orang lain yang menyebabkan penyakitnya disini HBM juga menggunakan mekanisme pertahanan ego proyeksi. HBM juga menggunakan mekanisme pertahanan ego represi dimana HBM merepresikan masalah yang ia alami, sedangkan mekanisme pertahanan ego 
somatisasi, dimana konflik yang dialami HBM di represi dan dimunculkan dalam bentuk keluhan fisik seperti pusing dan badan lemah maka sesuai dengan DSM-IV-TR derajat pertahanan yang dialami HBM adalah level of defense dysregulation.

Pada Aksis III dijumpai diagnosis dengan stroke iskemik karena dari anamnesis didapatkan keluhan badan terasa lemas, pusing, kaki dan tangan kiri lemah. 20 hari yang lalu awalnya HBM merasa kepala pusing saat sedang bekerja di rumah, kemudian tiba-tiba terjatuh dan tidak sadarkan diri lebih kurang 5 menit, HBM kemudian di bawa keluarga ke klinik di dekat rumah dan dirawat, selama dirawat kaki dan tangan kiri HBM terasa lemah dan sulit digerakan, lidah juga terasa berat dan bicara celat serta didapatkan riwayat stroke 7 tahun yang lalu dan riwayat hipertensi sejak 10 tahun yang lalu. Dari hasil pemeriksaan neurologi dijumpai kekuatan motorik sebelah kiri adalah 1. Pemeriksaan nervus VII sudut mulut tertarik ke kanan dan dari hasil pemeriksaan Head CT Scan kesan cerebral infarct pada periventikular kanan.

Pada Aksis IV tidak ada diagnosis karena tidak dijumpai adanya faktor stressor psikososial.

Pada Aksis V didiagnosis dengan GAF Scale 40-31 (beberapa disabilitas dalam hubungan dengan realita dan komunikasi, disabilitas berat dalam beberapa fungsi). GAF scale satu minggu terakhir: 7061 (beberapa gejala ringan atau beberapa disabilitas pada fungsi sosial, pekerjaan tetapi secara umum fungsi masih baik dan masih menjalin hubungan interpersonal) sedangkan GAF scale satu tahun terakhir: 80-71 (gejala sementara dapat diatasi, disabilitas ringan dalam sosial,pekerjaan dan lain-lain).

Beberapa keadaan yang memberikan gambaran prognosis yang baik pada kasus ini adalah tidak terdapatnya gangguan psikiatri sebelumnya, faktor pencetus jelas, awitan akut, tidak ada riwayat keluarga serta terdapatnya dukungan keluarga dan sosial yang baik. Sedangkan yang memberikan prognosis buruk adalah janda dan status sosioekonomi yang kurang. ${ }^{2}$

HBM diberikan terapi risperidon untuk psikotik akut nya karena risperidon merupakan obat golongan antipsikotik atipikal merupakan obat pilihan yang mempunyai efektivitas yang baik, efek samping minimal dan relatif aman dapat ditoleransi dengan lebih baik. ${ }^{15}$ Risperidon diberikan dengan dosis awal 1 mg karena dosis awal risperidon adalah: 1-2 mg/hari peroral untuk psikosis akut dibagi dua dosis tapi dapat juga diberikan satu kali perhari, kemudian dinaikan $1 \mathrm{mg} / \mathrm{hari}$ setiap hari sampai efektivitas yang diinginkan tercapai dengan dosis maksimum $16 \mathrm{mg} /$ hari. $^{9}$

Risperidon merupakan substrat bagi enzim CYP2D6, setiap obat yang bersifat inhibitor terhadap enzim CYP2D6 ini akan meningkatkan konsentrasi risperidon di plasma sedangkan obat yang bersifat inducer akan mempercepat pengurangan dosis risperidon dari plasma. Tetapi untuk risperidon arti klinisnya belum meyakinkan karena obat induk dan metabolitnya adalah zat aktif. ${ }^{10}$ Interaksi risperidon dengan obat yang diberikan oleh bagian neurologi yaitu citikolin, ranitidin dan kaptopril adalah: meminum risperidon bersama ranitidin dapat meningkatkan kadar ranitidin sehingga dapat meningkatkan risiko efek samping risperidon. ${ }^{10}$ Risperidon dapat meningkatkan efek antihipertensi. Sedangkan citicolin merupakan suplemen untuk otak belum diketahui interaksinya dengan risperidon. ${ }^{11}$

Pada follow up hari ke 7 , bicara-bicara sendiri, senyum-senyum sendiri dan marah-marah sudah berkurang, waham masih ada dan halusinasi masih ada tapi frekuensinya sudah berkurang, dosis risperidon dinaikan menjadi $2 \mathrm{mg}$ sekali sehari malam.

Pada follow up hari ke 14, bicara-bicara sendiri, senyum-senyum sendiri sudah jauh berkurang, marahmarah tidak ada lagi, waham sudah berkurang intensitasnya dan halusinasi frekuensinya jarang, dosis risperidon dinaikan menjadi $2 \mathrm{mg}$ dua kali sehari malam, obat dilanjutkan sampai pasien pulang dan pada waktu kontrol ke poliklinik satu minggu kemudian dosis obat diturunkan bila gejala psikotik sudah tidak ada dan kemudian dapat dihentikan.

Edukasi keluarga diberikan kepada keluarga OS agar mengetahui apa sebenarnya gangguan yang diderita OS, perjalanan penyakitnya, keterangan mengenai obat yang akan diberikan kepada OS baik tentang lamanya pengobatan maupun tentang efek samping obat yang akan diberikan. ${ }^{12}$

Rencana pemberian terapi suportif apabila insight pasien sudah baik dan keadaan umum pasien sudah membaik yang diberikan berupa reassurance 
yaitu memberikan dukungan, rasa aman dan ketentraman pada pasien sehingga dapat mengurangi penderitaannya dan explanation yang mencakup penjelasan tentang gangguan yang dialami pasien, penyebab dan perencanaan terapi. ${ }^{13}$

Pelayanan konsultasi merupakan suatu regu penolong yang merespon setiap permintaan dari bagian kedokteran lain untuk meminta bantuan dalam menegakkan diagnosis, terapi dan penatalaksanaan lain, misalnya pada pasien stroke iskemik yang dikirim ke psikiatri untuk melakukan CLP (ConsultationLiaison Psychiatry), maka pelayanan juga merupakan intervensi singkat kewilayah bidang lain, yang biasanya berakhir dengan sebuah jawaban konsul dan rencana tindakan penatalaksanaan. Kerjasama penanganan kasus gangguan psikotik pada stroke iskemik ini dilakukan secara dini melalui team work, kerjasama yang erat antara psikiater dan dokter rujukan harus terus dibina yang tentunya untuk kepentingan pasien itu sendiri. ${ }^{14}$

Keberadaan seorang psikiater sekiranya dapat membantu mengatasi gangguan psikiatrik yang timbul, dalam hal ini adalah psikotik, sehingga diharapkan dapat memperpanjang survival serta meningkatkan kualitas hidup pasien. ${ }^{14}$

\section{DAFTAR PUSTAKA}

1. Nemade R, Dombeck M. Symptom of psychiatry due to a medical condition. (diunduh Februari 2012). Tersedia dari: URL: HYPERLINK http://www.mentalhelp.net

2. Sadock BJ, Sadock VA. Mental disorders due to a general medical condition. Synopsis of psychiatry behavioral sciances/ clinical psychiatry. $10^{\text {th }}$ ed. Philadelphia: Lippincott Williams \& Wilkins; 2007.

3. Santos S, et al. Stroke-psychosis. description of two cases. Actas Esp Psiquaiatr. 2009; 37(4): 240-2.

4. Levenson JL. Stroke. Primary Psychiatry. 2007;14(9):37-40.
5. Chemerinski E, Robinson RG. The neuropsychiatry of stroke. Psychosomatics, 2000;41(1):5-14.

6. Robinson RG, Jorge R. Neuropsychiatry aspects of cerebrovascular disease. Dalam : Sadock BJ, Sadock VA, editor (penyunting). Comprehensive Textbook of Psychiatry. Volume I. Edisi ke-9. Philadelphia: Lippincott Williams \& Wilkins; 2009. hlm.420-35.

7. American Psychiatric Association. Diagnostic and statistical manual of mental disorders. 4thed text revision. Arlington: American Psychiatric Association; 2000.

8. Amir N. Penatalaksanaan pasien stroke dengan gangguan emosi. JIWA Majalah Psikiatri. Jakarta: Yayasan Kesehatan Jiwa Darmawangsa XXXI:1998;2:169-82.

9. Stahl SM. Essensial psychopharmacology the prescriber's guide. Edisi ke-1. Grady MM, editor (penyunting). UK: Press Syndicate of the University of Cambridge; 2005. hlm. 411-16.

10. Stahl SM. Essential psychopharmacology. Edisi ke-2. Cambridge: Cambridge University Press; 2002.

11. Monson K, Schoenstadt A. Drug interactions with risperidone. (diunduh Februari 2012). Tersedia dari: URL: HYPERLINK http://bipolar-disorder. emedtv.com

12. Center for Mental Health Services. Substance Abuse and Mental Health Services Administration. Evidence-based practices KITs. Training Frontliner Staff. Family Psychoeducation. U.S: Department of Health and Human Services; 2009.

13. Winston A, Rosenthal RN, Pinsker H. Introduction to supportive psychotherapy. Edisi ke-1 Arlington: American Psychiatric Publishing; 2004.

14. Waney AT. Consultation liaison psychiatry dan/atau psychosomatic medicine. Dalam: Jiwa Majalah Psikiatri. Jakarta: Yayasan Kesehatan Jiwa Darmawangsa; 2005. hlm.1-2. 